\title{
The Effect of Test Taking Strategy Instruction on Iranian High School Students' Performance on English Section of the University Entrance Examination and Their Attitude towards Using These Strategies
}

\author{
Fatemeh Takallou (Corresponding author) \\ Department of TEFL and English Literature, Payame Noor University, Iran \\ E-mail address: f.takallou@gmail.com \\ Freidoon Vahdany \\ Department of TEFL and English Literature, Payame Noor University, Iran \\ E-mail address: frvahdany@yahoo.com \\ Seyed Mahdi Araghi \\ Department of TEFL and English Literature, Payame Noor University, Iran \\ E-mail address: araghism@gmail.com \\ Amir Reza Nemat Tabrizi \\ Department of TEFL and English Literature, Payame Noor University, Iran \\ E-mail address: arnemati@yahoo.com
}

Received: 21-04- 2015

Published: 01-11- 2015
Accepted: 05-07- 2015

Advance Access Published: August 2015

doi:10.7575/aiac.ijalel.v.4n.6p.119
URL: http://dx.doi.org/10.7575/aiac.ijalel.v.4n.6p.119

\begin{abstract}
This paper reports on a study that investigated the effect of teaching test-taking strategies on Iranian high school students' performance on English section of the National University Entrance Examination (Konkoor). To do so, 273 male and female high school students participated in a workshop that lasted for four sessions. The participants were randomly divided into an experimental and a control group. In the beginning of the workshop, participants received a demographic questionnaire to see if they had taken part in a similar test-taking class which resulted in excluding some students from the groups. The groups were also homogenized regarding their language proficiency level by administering Oxford Placement Test (OPT). Therefore, 260 participants were left for the main study. Then, experimental group participated in the test-taking strategy workshop and control group worked on the previous samples of Konkoor examinations without any reference to test-taking strategies. At the end of the workshop, the attitude questionnaire was run in the experimental group to compile the group's opinions about the treatment. One month later, the students of both groups took Konkoor. The data were analyzed using an independent-samples t-test. The learners' responses to the attitude questionnaire were also analyzed quantitatively. The findings of this study indicated that Iranian high school students in the experimental group outperformed the control group on their Konkoor exam. Moreover, they had positive attitudes towards teaching and learning test-taking strategies. This study suggests that integrating such strategies in the teaching curriculum could be beneficial for the students.
\end{abstract}

Keywords: Test taking strategies, Attitude, Instruction, Language Performance

\section{Introduction}

Language test results, particularly high stakes tests, may play a highly significant role in the test takers' future life, helping to determine whether test takers get into their interested field of study or get their ideal job. In Iran, National University Entrance Examination which is called 'Konkoor' has the sole criterion for Iranian students' admission into public universities. Consequently, it has a crucial role in the test takers' future field of study and their prospective job, but many students with high GPA are seen to have weak performance in Konkoor. "For this reason, it may be crucial that beyond the standard orientation that is available for high-stakes tests, respondents have a sense as to how to enhance their performance on specific types of items and procedures found on such tests" (Cohen, 2012, p. 96). Many students are poorly prepared for test taking strategies and that the lack of "test-wiseness" is often responsible for test scores which do not accurately reflect the students' knowledge (Scruggs \& Mastropieri, 1995, p. 10).

Recent language testing research has focused on factors other than language proficiency that may be responsible for systematic variance in language test performance mainly in three areas: "characteristics of the testing procedure, including raters; the processes and strategies used by test takers in responding to test tasks; and the characteristics of the test takers" (Bachman, 2000, p. 10) which the processes and strategies used by test takers include test taking strategies. 
While differences in the test performance of different groups of test takers have been a long-standing interest among language testers, the past decades have seen increased research in this area, both in terms of the research approaches used and the areas investigated (Bachman, 2000).

According to Weir (2005), three main categories of test taker characteristics can be sub-divided into: physical/physiological, psychological characteristics, and experiential characteristics which means the degree of a test taker's familiarity with a particular test may affect the way the task is managed such as test taking strategies. On the whole, all three types of characteristics have the potential to affect test performance.

Based on previous studies (Cohen, 1984; Nevo, 1989; Phakiti, 2008; Radojevic, 2009; Rezaei, 2005), it seems that test taking strategies have a positive role in the students' test performance. Test taking strategies are acquired skills and if a student has learned some of the specific test taking strategies, that individual can expect to score considerably higher in tests than those with equal ability who have not learned any test taking strategies (Dobbin, 1984). Teachers can help their students by teaching them test taking strategies which they can employ under a test situation and motivate them to recognize the importance of these strategies and know how to benefit from them in order to achieve the desired outcome.

Research into teaching learners' test-taking strategies is rather scarce and the area is relatively under-explored. According to Cohen (2006) there is limited literature addressing the issue of strategy instruction for prospective respondents on high stakes standardized tests. Although many studies support the beneficial role of test-taking strategy, its instruction in a foreign language setting was rarely done for high school students specifically English language performance. In this direction, this paper examines the effect of teaching test taking strategies on Iranian high school students' performance on English section of Konkoor. Moreover, this study reviewed the participants' attitude regarding test-taking strategy instruction.

\subsection{Literature Review}

The challenge for language testing researchers is to identify the test taker characteristics that influence test performance and to model those test taker characteristics with test performance to measure and explain the major influences on test performance. According to Kunnan (1995), test-taker characteristics include personal characteristics, educational characteristics, as well as cognitive, psychological, and social characteristics. Brown (2004, cited in, Medina \& Neil, 1990) claims that standardized tests involve a number of types of test bias in many forms such as language, culture, race, gender and learning styles.

Test performance is also affected by individual characteristics that are not part of test takers' language ability. These may include test takers' cognitive and affective characteristics, their 'real world knowledge', and factors such as their age, sex, native language, educational and, socioeconomic background. Measurement specialists and language testers alike have tended to consider factors such as these as potential sources of test bias.

At the same time, these individual attributes may interact with aspects of the methods used in any given test, so that individuals with different backgrounds and personalities may perform differentially on different types of language tests. Another set of individual characteristics is 'test-wiseness' that includes a range of general strategies related to competent test taking, such as excluding as many alternatives as possible in multiple-choice items and then guessing among the ones remaining.

Test taking strategies enable learners to take advantage of the characteristics and the format of the test to improve their performance and increase scores in test taking situations (Rogers \& Harley, 1999). Considerable studies have indicated that, in the area of second or foreign language tests, there are certain types of strategies which are used by test takers during a test taking course (Cohen \& Upton, 2007; Hirano, 2009). According to Rogers and Harley (1999), test taking strategies enable learners to use the characteristics and format of a test to increase scores in a test taking situation. In addition, Hirano (2009, p. 158) argues that there are basically distinct types of strategies that respondents use as they do language tests: 1) language learner strategies (the way learners operationalized their basic skills of listening, reading, speaking and writing including the related skills of grammar, vocabulary, and translation), 2) test management strategies (i.e., "strategies for responding meaningfully to the test items and tasks", and 3) test-wiseness strategies (i.e., "strategies for using knowledge of test formats and other peripheral information to answer test items without going through the expected linguistic and cognitive processes").

In other study, Rupp et al. (2006) argued that different testing formats result in different strategy use. Thus, multiplechoice tests create a unique testing format and elicit specific strategy selection. For example, multiple-choice questions enable test takers to get clues about the important parts of the text and to ignore the rest of the parts not covered by the test questions. Unlike other reading comprehension tests that require free responses or summary recall, participants are aware of the advantages of the multiple-choice format and use the questions and options as indicators of which portion of the text tends to be more important or worth reading, especially under critical time constraints. According to Cruz (2013), while teaching test taking strategies, it is vital that the students also practice the strategies until they comprehend the importance of the techniques.

In an EFL setting, Rezaei (2005) investigated the impact of knowing and applying test taking strategies on the learners' language test performance taking an achievement language test and whether the degree the testees use test taking strategies vary in different sections of the test. He concluded that "performance on language tests can be improved if both language teachers and test designers have a better insight into different strategies that the students apply" (p. 27). 
In the next research, Phakiti (2008) examines the relationship of test takers' long-term strategic knowledge and actual strategy use to second language reading test performance over time. It was found that trait metacognitive strategy use directly and strongly affects trait cognitive strategy use and trait cognitive strategy use does not greatly affect state cognitive strategy use; trait metacognitive strategy use directly affects state metacognitive strategy use in a specific context which in turn directly affects state cognitive strategy use and state cognitive strategy use directly affects a specific language test performance to a varying degree.

A number of studies have been conducted on the instruction of test taking strategies which show that using test taking strategies does improve test scores in all age groups. The effects of training test taking strategies on students' performance on a school readiness test were investigated by Dreisbach and Keogh (1982). They found that trained students performed better than the other students and concluded that teaching test-taking strategies has an important influence on the test performance of students from non-majority backgrounds and should be taken into account in readiness assessment programs.

Zeidner, Klingman, and Papko, 1988 (cited in Wiersma, 1990) reported on a study with 497 fifth and sixth grade students. The training was implemented by homeroom teachers. The program consisted of five, one-hour sessions held two weeks apart. The content included time management and work schemes and relaxation techniques. Overall, they concluded that on the whole, the data pointed to the effectiveness of teacher-implemented training programs in meaningfully enhancing students' cognitive performance during test situations.

In another study, Amer (1993) investigated the effect of teaching a test taking strategy to high school students on their performance in EFL tests. His research findings showed a positive relationship between teaching test taking strategies and the corresponding test performance. Moreover, Obah (1993) examined the effects of teaching and practicing in one aspect of test taking strategies, time management. It was found that there was a positive relationship between teaching students test taking strategies, how they subsequently managed time, and improved their examination scores. The researcher has concluded that a very important aspect of academic success is knowing how to manage time within the examination itself.

Vattanapath and Jaiprayoon (1999) investigated the effectiveness of the teaching of test taking strategies for multiple choice English reading comprehension tests. The results of the study showed that the mean score on the English reading comprehension test obtained from the experimental group were significantly higher than that from the control group. Scharnagl (2004) also conducted an experimental study to examine the impact of additional instruction of test taking strategies on reading achievement of low-performing third-grade students. The results revealed that the experimental group who received additional instruction in test taking strategies also outperformed the control group who received regular instruction only.

Finally, Hirano (2009) stated that test taking strategy use and test performance are influenced by the language of response, language proficiency type, test method, and item types among other potential variables. Thus, reading teachers need to go beyond their traditional roles by providing opportunities for their students to become familiar with and apply such strategies.

\subsection{Research Questions}

This study attempted to answer the following research questions:

1. Does test-taking strategy training have any significant effect on high school students' performance on English section of University Entrance Examination (Konkoor)?

2. What is the learners' attitude towards using these strategies?

\section{Methodology}

\subsection{Participants}

The participants of the study were 273 male and female junior high school students in Iran, Tehran. After reviewing the demographic questionnaires completed by students and their performance on the standardized language proficiency test (OPT), 13 students were excluded from the study due to taking part in a similar test-taking training and having the language proficiency level above or below the pre-intermediate level. Therefore, 260 participants were left for the data analysis who were randomly divided into one experimental $(n=128)$ and one control group $(n=132)$. These students were chosen based on the convenience sampling.

\subsection{Instructional Package}

An instructional package was developed for the experimental group. It consisted of some general test-taking strategies, some specific test-taking techniques regarding multiple choice tests, and finally some useful tips about preparation for the exams. These strategies, techniques and tips were collected from several testing sites and testing books. In addition, the test-taking strategies introduced in the Rezaei's questionnaire (2005) were used as a part of this package.

The package was reviewed by two proficient Iranian EFL professors and three high school English language teachers. The professors' and teachers' views resulted in changing or omitting some of the parts and creating a Persian test taking strategy package. This package was piloted by 32 high school students who were representative of the actual participants in the study.

\subsection{Instruments}

The following instruments were employed in this study: 


\subsubsection{Oxford Placement Test}

This standardized language proficiency test was used in order to ensure that participants were at the same language proficiency level before starting the treatment. This test includes 60 items with maximum score of 60 and measures testtakers' grammar, vocabulary, and reading knowledge. The scores between 30-39 are grouped at lower intermediate level. Therefore, since most of the participants' scores were in this band score, their level of language proficiency was assessed as lower intermediate and the scores below and above this level were removed from final analysis.

\subsubsection{English Section of Konkoor Examination}

This test is always designed by Sanjesh Organization. In reference to the validity of this test, Brown and Rolfe (2004) stated that "formal assessments such as standardized test have an established validity" (p. 194). Konkoor examination is reviewed by an independent panel of educators who examine each item to make sure it aligns with the curriculum and checked for suitability and potential bias. Items are field tested and approved by Sanjesh Organization. Since Konkoor examination is prepared by a panel, absence of bias, internal reliability and construct validity have already been established. This test consists of 25 multiple choice items which are usually designed in three parts of grammar, vocabulary, and reading comprehension (see Appendix A).

\subsubsection{Demographic Questionnaire}

This researcher designed Persian (native language of the participants) questionnaire asked participants to report full name, name of high school, whether they had participated in any extra educational classes related to the test-taking strategies, and its duration (see Appendix B).

\subsubsection{Attitude Questionnaire}

It was a 4-point Likert rating-scale questionnaire, from 1(Strongly Disagree), 2(Disagree), 3(Agree) and 4(Strongly Agree) adopted from Pour-Mohammadi and Jafre (2011). The questionnaire was modified after running it in a pilot group of 32 students with characteristics similar to those of the real participants. It should be mentioned that this questionnaire was translated into the participants' native language (Persian) and conducted at the end of the workshop to investigate the students' impressions and opinions about the teaching of test-taking strategies as well as their learning experience. (see Appendix C).

\subsection{Procedure}

In order to assess the reliability of the attitude questionnaire, it was piloted on 32 high school students having characteristics similar to the target group.

To accomplish the purpose of the study the following procedures were carried out in five steps:

Step 1: All students received the OPT test in one session before starting the workshop to ensure their homogeneity regarding language proficiency level.

Step 2: All students completed the researcher-made demographic questionnaire to see if they already had taken part in a test taking class.

Step 3: Experimental group participated in the test-taking strategy instruction which lasted for four sessions, while control group worked on the previous samples of Konkoor exam without any reference to test-taking strategies. The participants in the experimental group were given training in test-taking strategies for multiple-choice English language tests as supplementary teaching to their regular English language classroom. Each workshop lasted for two hours near the end of the semester. In order to enable the participants to be familiar with the test-taking strategies, the researcher clarified and modeled how each strategy must be used in the processes of answering multiple-choice items in the previous Konkoor exams. For example, learners were taught explicitly that in answering a particular question, they had to utilize relevant content information in other test items and options. In Reading Comprehension questions, they had to certainly review the questions before they read the text and if a question asks for a number or a name, they should scan the text to find the correct answer. Moreover, they were informed that while reading a text, they must try to keep in mind all the details as in answering the questions they may not find any time to go back and scan it. It was mentioned that it is a good idea to look for an association, usually semantic or grammatical, between a word or phrase in the stem and a word or phrase in one of the options which cues the answer. They were also told that analysis of the structure of words (prefix, suffix and stem) would help them to find the meanings of unknown words in tests on vocabulary and transition words in a sentence would help them to get the meaning of a particular word or the whole sentence. Moreover, they received some strategies in managing their time since Konkoor is a kind of speed test that most of the test takers find time shortage problems in it. Other related strategies regarding the grammar items and how to skip the irrelevant distractors in answering them were also presented.

Step 4: Next, the attitude questionnaire was taken at the end of the workshop to elicit information about the participants' likes, dislikes, and overall ideas about the effect of teaching and learning of test-taking strategies on improving their performance on multiple-choice English language tests.

Step 5: All the students took Konkoor one month later and after receiving the results; their ranks and English section percentages were collected and analyzed. 


\section{Results and Discussion}

In order to provide answer for the first research question, "Does test-taking strategy training have any significant effect on high school students' performance on English section of Konkoor?", after ensuring the normality of the scores distribution by running Kolmogorov- Smirnov test (the non-significant results, Sig. $\geq .05$ ), an independent-samples ttest was used to compare the control and experimental group's performance on English section of Konkoor. Results are presented in the table below.

Table 1. Independent Samples Test for the Groups' Performance on English Section of Konkoor

\begin{tabular}{|c|c|c|c|c|c|c|c|c|c|c|}
\hline & & \multicolumn{2}{|c|}{$\begin{array}{l}\text { Levene's Test } \\
\text { for Equality } \\
\text { of Variances }\end{array}$} & \multicolumn{7}{|c|}{ t-test for Equality of Means } \\
\hline & & \multirow[t]{2}{*}{$\mathrm{F}$} & \multirow[t]{2}{*}{ Sig. } & \multirow[t]{2}{*}{$\mathrm{t}$} & \multirow[t]{2}{*}{$\overline{\mathrm{Df}}$} & \multirow{2}{*}{$\begin{array}{l}\text { Sig. } \\
(2- \\
\text { taile } \\
\text { d) }\end{array}$} & \multirow[t]{2}{*}{$\begin{array}{c}\text { Mean } \\
\text { Differe } \\
\text { nce }\end{array}$} & \multirow{2}{*}{$\begin{array}{c}\text { Std. } \\
\text { Error } \\
\text { Differe } \\
\text { nce }\end{array}$} & \multicolumn{2}{|c|}{$\begin{array}{l}95 \% \text { Confidence } \\
\text { Interval of the } \\
\text { Difference }\end{array}$} \\
\hline & & & & & & & & & Lower & Upper \\
\hline \multirow{3}{*}{ 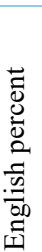 } & Equal & .27 & .59 & 4.11 & 258 & .00 & 9.32 & 2.26 & 4.85 & 13.78 \\
\hline & assumed & & & & & & & & & \\
\hline & $\begin{array}{l}\text { Equal } \\
\text { variances not } \\
\text { assumed }\end{array}$ & & & 4.10 & 256.8 & .00 & 9.32 & 2.26 & 4.85 & 13.78 \\
\hline
\end{tabular}

The first section of the output box has presented the results of Levene's test for uniformity of variances. This examined whether the variance of scores for the two groups (experimental and control) was the same. Since the Sig. value for Levene's test Levene's test was (.59) which is larger than the cut-off of (.05) the assumption of similar variances was observed.

Moreover, since the value (.00) in the Sig. (2-tailed) column was less than (.05), there was a significant difference in the mean scores on the dependent variable for each of the two groups. The mean difference between the two groups was also displayed, along with $95 \%$ confidence interval of the difference showing the lower value and the upper value.

Effect size statistics gave an indication of the extent of the differences between the groups. The most commonly used effect size namely eta squared was computed using the information provided in the output and the obtained value was. 015. The guidelines (proposed by Cohen 1988, pp. 284-7) for interpreting this value are: $1=$ small effect, . $3=$ medium effect,. 5 = large effect. It was seen that the effect size of .015 is small effect. Explicated as a percentage (eta square value was multiplied by 100), 1.5 percent of the variance in English posttest scores was explained by the two groups. Thus, the independent-samples t-test was conducted to compare the performance on English section for control and experimental groups. There was significant difference in scores for control $(M=15.79 \%, S D=18.59)$ and experimental group $(M=25.11 \%, S D=17.95 ; t(258)=4.11, p=.00$, two-tailed). The magnitude of the differences in the means (mean difference $=9.32 \%, 95 \% \mathrm{CI}$ : 4.85 to 13.78 ) was small (eta squared $=.015$ ). Thus, the answer to the third research question was yes implying that test-taking strategy training had significant effect on high school students' performance on English section of Konkoor.

Regarding the second research question, "What is the learners' attitude towards using these strategies?", The participants expressed their highest positive attitude towards items (11 and 14) respectively. Item 11 investigated the participants' viewpoint with respect to allotting "more time to practice test-taking strategies" $(M=3.44)$. Item 14 inspected their attitudes in relation to "the role of test-taking strategies in enabling them to read all options before choosing the best answer" $(M=3.40)$. In contrast, the lowest mean ranks were reported for items (3 and 13) respectively. Item 3 investigated the participants' stance with reference to "the impact of learning test-taking strategies in making them more anxious in taking tests." $(M=1.65)$. Item 13 looked at "how they felt after studying test-taking strategies" $(M=$ 1.74).

Regarding the diversity with which they rated the items of the attitude questionnaire, items (8 and 6) had the highest variation respectively. Item 8 examined the participants' attitude with reference to "the necessity of learning test-taking strategies." $(\mathrm{SD}=.92)$. Item 6 evaluated the participants' attitude in relation to "teaching Test-taking strategies in class." ( $\mathrm{SD}=.81)$. On the other hand, items (5 and 1) reflected the least degree of variance implying that the respondents were highly consistent in their responses to these items. Item 5 assessed their viewpoints towards "usefulness of learning test-taking strategies to go through the test more carefully." ( $\mathrm{SD}=.64)$. Item 1 appraised their reflection towards "studying test-taking strategies." ( $\mathrm{SD}=.65)$. The following table (Table 2) presents mean and standard deviation for the items of the attitude questionnaire. 
Table 2. Descriptive Statistics for the Items of the Test Taking Strategy Use Questionnaire

\begin{tabular}{|c|c|c|}
\hline & Mean & Std. Deviation \\
\hline 1. I enjoyed studying test-taking strategies. & 3.21 & .65 \\
\hline $\begin{array}{l}\text { 2. I feel that I can do the test better after learning test- } \\
\text { taking strategies. }\end{array}$ & 3.11 & .69 \\
\hline $\begin{array}{l}\text { 3. Learning test-taking strategies makes me more } \\
\text { anxious in taking tests. }\end{array}$ & 1.65 & .71 \\
\hline $\begin{array}{l}\text { 4. Learning test-taking strategies assists in time } \\
\text { management more effectively. }\end{array}$ & 3.32 & .78 \\
\hline $\begin{array}{l}\text { 5. Learning test-taking strategies helps me go through the } \\
\text { test more carefully. }\end{array}$ & 3.06 & .64 \\
\hline 6. Test-taking strategies should be taught in class. & 3.08 & .81 \\
\hline 7 Test-taking strategies should be taught out of class. & 3.24 & .78 \\
\hline 8. I think it is not necessary to learn test-taking strategies. & 2.66 & .92 \\
\hline $\begin{array}{l}\text { 9. Learning test-taking strategies helped me guess } \\
\text { effectively. }\end{array}$ & 3.08 & .68 \\
\hline $\begin{array}{l}\text { 10. I can apply test-taking strategies in the real situation } \\
\text { while taking tests. }\end{array}$ & 3.04 & .80 \\
\hline $\begin{array}{l}\text { 11. There should be more time to practice test-taking } \\
\text { strategies. }\end{array}$ & 3.44 & .69 \\
\hline $\begin{array}{l}\text { 12. Learning test-taking strategies enables me to do the } \\
\text { easy items first, skip the difficult items and answer } \\
\text { them later }\end{array}$ & 3.03 & .73 \\
\hline $\begin{array}{l}\text { 13. After studying test-taking strategies, I still do the test } \\
\text { from the first item to the last item respectively without } \\
\text { being concerned about the marks and how they are allotted. }\end{array}$ & 1.74 & .70 \\
\hline $\begin{array}{l}\text { 14. Learning test-taking strategies enables me to read all } \\
\text { options before choosing the best answer. }\end{array}$ & 3.40 & .80 \\
\hline $\begin{array}{l}\text { 15. Learning test-taking strategies made me get a higher } \\
\text { score because I can take a test effectively, and I can } \\
\text { manage time more appropriately. }\end{array}$ & 3.14 & .74 \\
\hline
\end{tabular}

The Figure 1 also illustrates the participants' responses to attitude questionnaire.

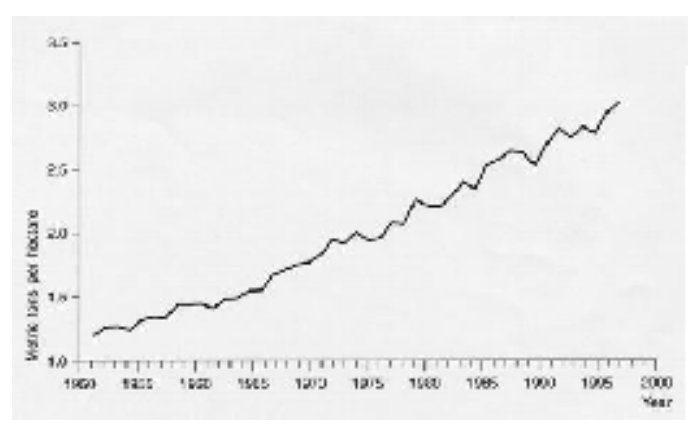

Figure 1. The Trend of Economic Development 
In general, the results of this study along with those of other related studies (Dreisbach and Keogh, 1982; Zeidner, Klingman, and Papko, 1988; Amer, 1993; Obah, 1993; Vattanapath and Jaiprayoon, 1999; Scharnagl, 2004; Hirano, 2009) suggest support for training in test-taking strategies. Its positive outcomes encourage EFL instructors to provide such instructions. On the basis of the data by means of English section percentage in Konkoor, in general the experimental group outperformed the control group. In addition, with regards to the attitudes of the participants towards the teaching and learning of test-taking strategies for multiple choice tests, the participants generally depicted positive attitudes. In item 11, they expressed their need for more time to practice test-taking strategies. It showed that having just test-taking strategy workshop did not suffice them. Item 6, test-taking strategies should be taught in class, represented the participants' positive attitude towards having test-taking strategy instruction while they were studying in their high school to integrate these strategies with their courses. Perhaps, one reason for such a strong agreement on the importance of teaching and learning test-taking strategies in the class could be the fact that most teachers may not recognize the significance of the teaching of test-taking strategies. Moreover, the results also revealed that most of the participants strongly agreed that the training helped them to read all options before choosing the best answer. Furthermore, item 13 revealed that learning test-taking strategies decreased the participants' anxiety in taking tests as they became familiar with test format and some test-taking strategies.

This result is in consistence with the previous researchers' claim that training of test-taking strategies can lead to positive outcomes (Amer, 1993; Obah, 1993; Vattanapath and Jaiprayoon, 1999; Scharnagl, 2004; Hirano, 2009). According to the findings in their studies, these researchers also suggested that teachers must emphasize the appropriate use of test-taking strategies so that students can know what they should do during taking a test. They also reported that teaching test-taking strategies could decrease students' test anxiety. As teaching test-taking strategies improves students' test performance, they would be more confident and motivated to have an active role in learning. As Nourdad (2015) states, some probable causes of significant effect of test-taking strategies in assisting test-takers solve the problems when they are taking tests are changing their attitudes toward testing and decreasing their test anxiety as a consequence. Investigations in general education (Kalechstein, Hocevar \& Kalechstein, 1998) and applied linguistics (Elkhafaifi, 2005; Golchi, 2012) have demonstrated that testwiseness co-vary with test anxiety. Furthermore, according to Arnold (2000), practicing test-taking strategies is one sort of systematic desensitization, which reduces the amount of anxiety. It means that, experiencing factors of anxiety-making helps language learners gain emotional and mental control, and eventually they can participate in the situation effectively. To sum up, teaching and learning test-taking strategies can be valuable to boost students' attitudes towards tests and language learning, to help them to have better performance on tests, and more significantly to lower their test anxiety. Overall, the findings of this study along with those of other related studies suggest support for teaching test-taking strategies and encouraging EFL instructors to provide such instructions.

\section{Conclusion}

Overall, it became clear that test-taking strategy training could have a meaningful effect on students' attitude and test performance. Teaching such strategies to high school students and motivating them to apply them can encourage them make logical guesses, have better achievement, solve problems or difficulties while taking tests. It also reduces test anxiety. Thus, it can be concluded that integrating such strategies in teaching curriculum as to be instructed on the regular and disciplined basis could be beneficial for the students. The findings of this study indicated that Iranian high school students in the experimental group outperformed the control group who did not take part in the test-taking strategy workshop. Moreover, they have positive attitudes towards teaching and learning test-taking strategies for multiple-choice English tests. However, due to time limitation and administration, this study was performed in a fourday workshop which lasted around 8 hours. Hence, this study could be carried out again integrating into their classroom schedule for more practice of taking tests. Moreover, this research might be improved in future replications by considering other test formats such as essay tests, true false tests, matching tests, and so forth. In short, such studies would provide helpful guidelines for integrating test-taking strategy instruction in all levels of EFL contexts.

\section{References}

Amer, A. (1993). Teaching EFL students to use a test-taking strategy. Language Testing, 10(1), 71-77.

Arnold, J, (2000). Seeing through listening comprehension exam anxiety. TESOL Quarterly, 34(4), 777-786.

Bachman, L. (2000). Modern language testing at the turn of the century: Assuring that what we count counts. Language Testing, 17(1), 1-42.

Brown, H.D. (2004). Language assessment: Principles and classroom practices. White Plains, NY: Pearson Education

Cohen, A.D. (1984). On taking language tests: What the students report. Language Testing, 1(1), 70-81.

Cohen, A.D. (2006). The coming of age of research on test-taking strategies. Language Assessment Quarterly, 3(4), 307-331.

Cohen, A.D. (2012). Test-taking strategies. In C. Coombe, P. Davidson, B. O’Sullivan \& S. Stoynoff (Eds.), The Cambridge guide to second language assessment (pp. 96-104). Cambridge: Cambridge University Press.

Cohen, A. \& Upton, T. (2007). I want to go back to the text: Response strategies on the reading subtest of the new TOEFL. Language Testing, 24(2), 209-250. Retrieved March, 21, 2014, from http://dx.doi.org/10.1177/0265532207076364. 
Cruz, B. (2013). Strategy instruction and its effectiveness in passing the mathematical portion of the CAHSEE (Unpublished master's thesis). California State University, Northridge.

Dobbin, J. E. (1984). How to take a test. Princeton, NY: Educational Testing Services.

Dreisbach, M. \& Keogh, B. (1982). Testwiseness as a factor in readiness test performance of young Mexican-American children. Journal of Educational Psychology, 74(2), 224-229.

Elkhafaifi, H. (2005). Listening comprehension and anxiety in the Arabic language classroom. The Modern Language Journal, 89 (2), 206-220.

Golchi, M.M. (2012). Listening anxiety and its relationship with listening strategy use and listening comprehension among Iranian IELTS learners. International Journal of English Linguistics, 2 (4), 115-128.

Hirano, K. (2009). Research on test-taking strategies in L2 reading. Bull. Joetsu Uni. Educ., 28, 157-165.

Kalechstein, P.B., Hocevar, D \& Kalechstein, M, (1998). Effects of test-wiseness training on test anxiety, locus of control and reading achievement in elementary school children. Anxiety Research, 1 (3), 247-261.

Kunnan, A. (1995). Test takers' Characteristics and Test Performance: a Structural Modeling Approach. Cambridge: Cambridge University Press.

Mastropieri, M.A., \& Scruggs, T.E. (1995). Teaching science to students with disabilities in general education settings. Teaching Exceptional Children, 27 (4), 10-15.

Nevo, N. (1989). Test-taking strategies on a multiple-choice test of reading comprehension. Language Testing, 6 (2), 199-215.

Nourdad, N. (2015). Gender and major differences in test-taking strategies and EFL. International Journal of English Language, Literature and Humanities, 2(4), 361-373.

Obah, T. (1993). Teaching an Examination Strategy to Technology Oriented University Students in Nigeria: The (PWR) Plan. Review of ELT, 3(1), 80-86.

Phakiti, A. (2008). Construct validation of Bachman and Palmer's (1996) strategic competence model over time in EFL reading tests. Language Testing, 25(2), 237. Retrieved April, 11, 2014, from http://dx.doi.org/10.1177/0265532207086783.

Pour-Mohammadi, M., \& Jafre, M. Z. (2011). Attitudes towards teaching and learning test-taking strategies for reading comprehension tests: The case of Iranian EFL undergraduates. Journal of Studies in Education, 1(1), 1-12.

Radojevic, N. (2009). Exploring the use of effective learning strategies to increase students' reading comprehension and test taking skills (Unpublished master's thesis). Brock University, Saint Catharines, Ontario.

Rezaei, A. (2005). Test-taking strategies and performance in language achievement tests. Pazhuhesh-e Zabanha-ye Khareji, 20, 27-50.

Rogers, W., \& Harley, D. (1999). An empirical comparison of three-and four-choice items and tests: Susceptibility to test-wiseness and internal consistency reliability. Educational and Psychological Measurement, 59(2), 234. Retrieved from, July, 10, 2014, from http://dx.doi.org/10.1177/00131649921969820.

Rupp, A. A., Ferne, T., Choi, H. (2006). How assessing reading comprehension with multiple-choice questions shapes the construct: A cognitive processing perspective. Language Testing, 23(4), 441-474.

Scharnagl, T. M. (2004). The effects of test-taking strategies on students' reading achievement (Unpublished doctoral dissertation). Union Institute and University, United States, Ohio.

Vattanapath, R., \& Jaiprayoon, K. (1999). An assessment of the effectiveness of teaching test-taking strategies for multiple-choice English reading comprehension tests. Occasional Papers, 8, 57-71.

Weir, C.J. (2005). Language Testing and Validation: An Evidence-Based Approach, Basingstoke: Palgrave Macmillan.

Wiersma, W. (1990). Educational measurement and testing. Allyn and Bacon: Boston.

\section{Appendix A: Sample of Konkoor English Section}

Time: 20 minutes

\section{Part A: Grammar and Vocabulary}

Questions 1-11 are incomplete sentences. Beneath each sentence you will see four words or phrases marked (1), (2), (3), and (4). Choose the one word or phrase that best completes the sentence. Then mark the correct choice on your answer sheet.

1- Does Mary know whom ----------- at the last party?
1) they met
2) they meet
3) do they meet
4) did they meet

2- The teacher was ----------- tired that she could not continue teaching.
1) as
2) too
3) such
4) very 
3- A: What's up? You look worried.

B: I am. My wife is sick. I think she ---------- wrong medicine.
1) may take
2) should take
3) may have taken
4) should have taken

4) I have never had a good ----------- for learning poems.

1) report 2) memory 3) hobby4) influence

5- She is very good at ----------- her duties.

$\begin{array}{llll}\text { 1) winning } & \text { 2) releasing } & \text { 3) following } & 4 \text { ) handling }\end{array}$

6- Few people would ---------- that something should be done to reduce the level of the crime.

$\begin{array}{lll}\text { 1) distract } & \text { 2) disagree } & \text { 3) suffer 4) react }\end{array}$

7- "I am going to ask each of you to give a/an -----------," the teacher said.

$\begin{array}{llll}\text { 1) extinction } & 2 \text { ) permission } & 3 \text { ) presentation } & \text { 4) communication }\end{array}$

8- Vitamins cannot be ---------- by our bodies.

$\begin{array}{llll}\text { 1) observed } & \text { 2) explored } & \text { 3) forwarded } & \text { 4) manufactured }\end{array}$

9- Our professor is always ----------- to talk to his students.
1) probable
2) flexible
3) advisable
4) available

10- This building had ----------- been used as a hotel.
1) similarly
2) previously
3) reasonably
4) interchangeably

11- They found a rock with gold in it, buried in the earth's surface.
1) straightly
2) efficiently
3) rapidly
4) deeply

\section{Part B: Cloze Test}

Directions: Questions 12-16 are related to the following passage. Read the passage and decide which choice (1), (2), (3), or (4) best fits each space. Then mark your answer sheet.

Try (12) --------- make your oral report too long. Include only the most important points. Work hard on your introduction and conclusion. These are what your (13) ---------- will remember most. The most important thing is to practice. Read your report out load. If it is long, (14) ----------- it carefully to realize how to make it shorter. Try changing the tone of your voice and the speed of your speaking. Next, read it to a small group of friends. Ask them to (15) what they think you can do to make it better. If you want to be successful, these are the steps you need to take whether you like it (16)

\begin{tabular}{|c|c|c|c|}
\hline 1) do not & 2) you not & \multicolumn{2}{|c|}{ 3) to not 4) not to } \\
\hline 1) audience & 2) issues 3) sample & 4) $r$ & ties \\
\hline 1) release & 2) predict & 3) examine & 4) magnify \\
\hline 1) bother & 2) suggest & 3) enhance & 4) concentrate \\
\hline 1) or you not & 2) not & 3) does not & 4) or not \\
\hline
\end{tabular}

\section{Part C: Reading Comprehension Directions}

In this part of the test, you will read two passages. Each passage is followed by four questions. Answer the questions by choosing the best choice (1), (2), (3), or (4). Then mark your answer sheet.

\section{PASSAGE 1:}

The first time I came to the Herault, after a ten-hour train ride from Paris to Montpellier, I caught a bus to the old village where my friend Sarah had bought a house. When I got there an hour and a half later, despite the fact that I'd been riding on a modern bus, I had the sense that I'd moved back 700 years. Sarah's house is made of stone, a few hundred years old, typical of the kind of place for sale cheaply here. Like actually all the village houses it's attached to the neighboring ones - so although the village is small it feels heavily populated, everybody living close together, always somebody leaning out of the window or sitting in front of the door. Inside, it is dark and cool. When Sarah bought the house, it had cold running water, some missing floors, and the fireplace didn't work.

17- How long did it take the writer to get to the place where her friend's house was?
1) Ten hours
2) Longer than a day

3) One and a half hours 4) Eleven and a half hours

18- All of the following are true about Sarah's house EXCEPT that it was ---------.
1) made of stone
2) built over 700 years ago 
3) connected to other houses 4) located in a crowded village

19- It can be understood from the passage that people living in the village

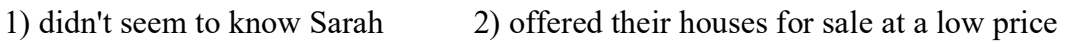

3) were probably friendly towards each other 4) went into their house when the writer arrived

20- It can be understood from the passage that when Sarah bought her house it was ---------.

1) good enough to live in 2) required some repairs

3 ) in the same condition as the other houses 4) older than the other houses in the village

21- Which of the following questions does the passage answer?

1) Did anyone help Sarah to fix her house?

2) How did the author happen to know Sarah?

3) Why did the author travel 700 years back in time?

4) Did the author walk from Montpellier to her friend's house?

\section{PASSAGE 2:}

To obtain power from the sun's rays is to use nuclear power developed at no expense in a laboratory 93 million miles away. For the bright energy of the sun is maintained by nuclear transformation of chemical elements occurring in the sun's interior at temperatures of many million degrees, and at pressures of many million atmospheres. The resources of solar power are enormous. If 100 per cent efficiency could be secured in the transformation of radiant solar energy into mechanical work, a horsepower per square yard of ground surface would be available under cloudless skies. The expense of collecting solar energy still prevents its competition with the usual power sources. Yet, unless the vague promise of safe thermonuclear power from oceans becomes realized, solar power must supply the enormous and growing requirements of children within two centuries. Because the ground sources (coal, oil and uranium) may be used up soon, they will become more costly than solar power.

22- According to the reading, what do we need to convert sunrays to energy?

1) Thermonuclear power sources.

2) A constant resource of chemicals.

3) A laboratory millions of miles away.

4) A cloudless sky at temperatures of enormous degrees.

23- The writer points out that solar energy is not used on a large scale -

1) though it is clean and safe

2) because the expense of controlling it is enormous

3) because it can create some dangers to the environment

4) since it is costly and less cost-effective than other sources of energy

24- Which of the following is the best topic for the reading?

1) Solar energy: an impossible energy source 2) Solar energy: facts and realities

3) Expenses of using solar energy 4) Different sources of energy

25- According to the reading, an alternative to solar energy can be

1) ocean thermonuclear power 2) energy from fossils

3) radiant energy 4) nuclear power

\section{Appendix B: Demographic Questionnaire}

Full name:

Name of high school:

Dear student, would you please read each of the following questions carefully and choose one of the choices, which correspond to you. Your answers in this questionnaire are not used in evaluating your knowledge.

1- Have you ever taken part in an educational class in or out of your high school?
A) Yes
B) No

2- If your answer to Question 1 is 'Yes', what kind of class have you taken part?

$\begin{array}{lll}\text { A) course book } & \text { B) English class C) Preparation class for Konkoor }\end{array}$

D) Others, please name them.

3- How long did you take part in the above-mentioned class or classes?

4) Do you have any English certificates?
A) Yes
B) No 
5- If your answer to Question 4 is 'Yes', what kind of certificate do you have?

6- Have you ever taken part in a pilot test of Konkoor?
A) Yes
B) No

7- Your father's educational degree:
A) Illiterate
B) Elementary school
C) Guidance school
D) High school
E) Diploma
F) Associate's degree
G) Bachelor and above bachelor

8- Your mother's educational degree:
A) Illiterate
B) Elementary school
C) Guidance school
D) High school E) Diploma

F) Associate's degree

G) Bachelor and above bachelor

9- If you like, please mention your parents' occupation.

A) Father:

B) Mother:

\section{Appendix C: Attitude Questionnaire}

Full name:

Name of high school:

The Likert Rating-Scale Questionnaire: (Students' Attitude about Teaching and Learning

Test-Taking Strategies)

Please read each of the following statements carefully and choose one of the choices.

1. I enjoyed studying test-taking strategies.

A. Strongly disagree B. Disagree C. Agree D. Strongly agree

2. I feel that I can do the test better after learning test-taking strategies.

A. Strongly disagree B. Disagree C. Agree D. Strongly agree

*3. Learning test-taking strategies makes me more anxious in taking tests.

A. Strongly disagree B. Disagree C. Agree D. Strongly agree

4. Learning test-taking strategies assists in time management more effectively.

A. Strongly disagree B. Disagree C. Agree D. Strongly agree

5. Learning test-taking strategies helps me go through the test more carefully.

A. Strongly disagree B. Disagree C. Agree D. Strongly agree

6. Test-taking strategies should be taught in class.

A. Strongly disagree B. Disagree C. Agree D. Strongly agree

7. Test-taking strategies should be taught out of class.

A. Strongly disagree B. Disagree C. Agree D. Strongly agree

*8. I think it is not necessary to learn test-taking strategies.

A. Strongly disagree B. Disagree C. Agree D. Strongly agree

9. Learning test-taking strategies helped me guess effectively.

A. Strongly disagree B. Disagree C. Agree D. Strongly agree

10. I can apply test-taking strategies in the real situation while taking tests.

A. Strongly disagree B. Disagree C. Agree D. Strongly agree

11. There should be more time to practice test-taking strategies.

A. Strongly disagree B. Disagree C. Agree D. Strongly agree

12. Learning test-taking strategies enables me to do the easy items first, skip the difficult items and answer them later

A. Strongly disagree B. Disagree C. Agree D. Strongly agree

*13. After studying test-taking strategies, I still do the test from the first item to the last item respectively without being concerned about the marks and how they are allotted.

A. Strongly disagree B. Disagree C. Agree D. Strongly agree

14. Learning test-taking strategies enables me to read all options before choosing the best answer.

A. Strongly disagree B. Disagree C. Agree D. Strongly agree

15. Learning test-taking strategies made me get a higher score because I can take a test effectively, and I can manage time more appropriately.

A. Strongly disagree B. Disagree C. Agree D. Strongly agree

*= Negative question 